\title{
Cardiac fibroma in a neonate
}

\author{
Sanjay P. Prabhu $\cdot$ Edward Y. Lee
}

Received: 24 June 2009 /Revised: 2 August 2009 / Accepted: 24 August 2009 / Published online: 12 September 2009

(C) Springer-Verlag 2009

A 1-week-old boy with a prenatal diagnosis of a cardiac mass underwent a cardiac MRI examination, which showed a large mass arising from the lateral wall of the left ventricle. This mass was isointense on $\mathrm{T} 1-\mathrm{W}$ and slightly hyperintense on $\mathrm{T} 2-\mathrm{W}$ images compared to the adjacent myocardium. On post-contrast dynamic MRI, the mass showed no substantial contrast enhancement on the early phase image (Fig. 1, arrows). On the delayed image, avid peripheral contrast enhancement (Fig. 2, arrows) of the mass with a hypointense core is seen (curved arrow).

Cardiac fibroma is the second most common childhood cardiac tumor [1]. Although benign, patients may become symptomatic due to arrhythmias, valvular dysfunction, or blood flow obstruction. Cardiac fibromas are firm masses

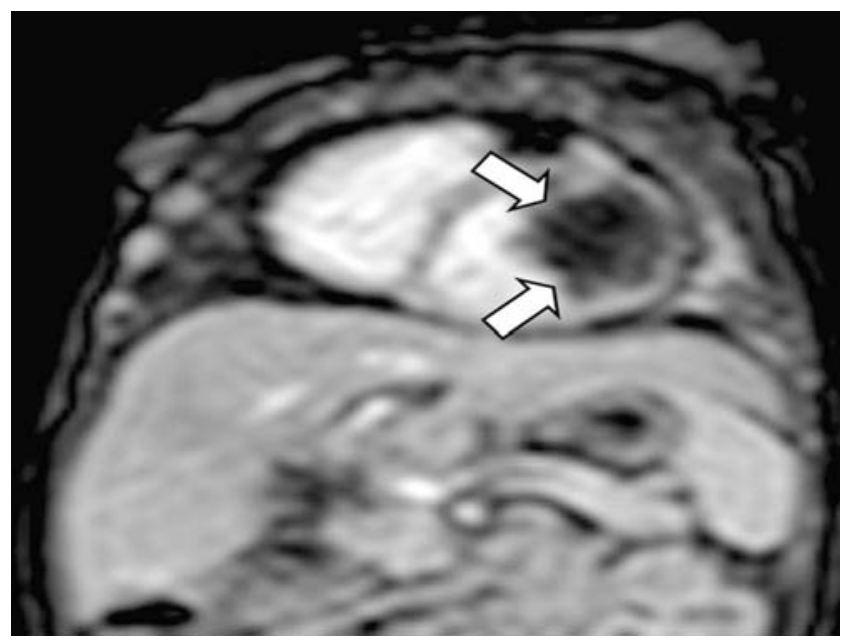

Fig. 1 Coronal post-contrast MRI

\footnotetext{
S. P. Prabhu $\cdot$ E. Y. Lee $(\bowtie)$

Department of Radiology,

Children's Hospital Boston and Harvard Medical School,

300 Longwood Ave.,

Boston, MA 02115, USA

e-mail: Edward.Lee@childrens.harvard.edu
}

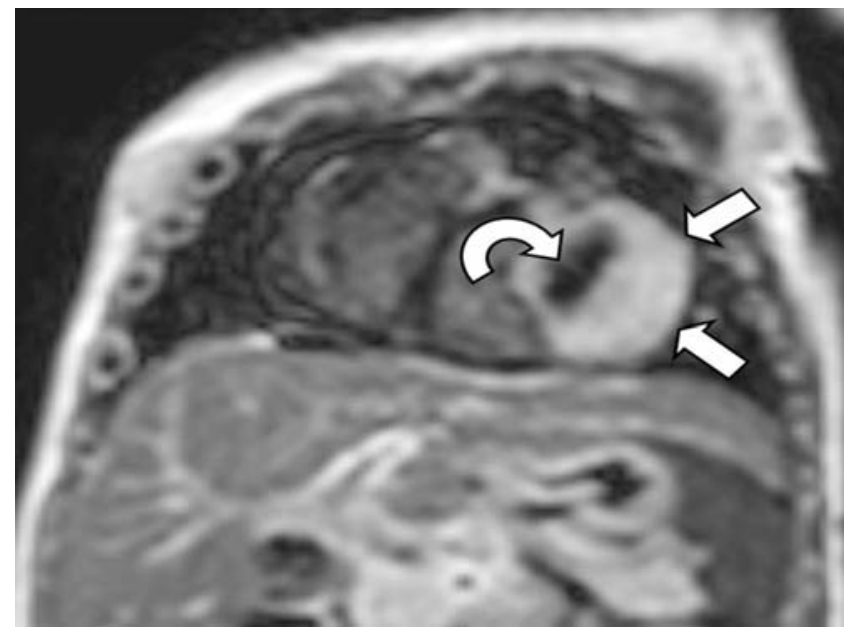

Fig. 2 Coronal post-contrast MRI 10 mins after contrast media administration

typically originating in the ventricular septum or ventricular free wall. A variable degree of peripheral contrast enhancement of the mass associated with a hypo-intense core, which reflects the area of reduced vascularity, is a characteristic MRI finding, as seen in our case. Although complete surgical resection is the preferred choice of management in symptomatic children [2], our patient was asymptomatic and is currently being carefully observed.

Acknowledgement Case courtesy of Oscar Benavidez, M.D., pediatric cardiologist, Children's Hospital Boston.

\section{References}

1. Basso C, Valente M, Poletti A et al (1997) Surgical pathology of primary cardiac and pericardial tumors. Eur J Cardiothorac Surg 12:730-737, discussion 737-738

2. Cho JM, Danielson GK, Puga FJ et al (2003) Surgical resection of ventricular cardiac fibromas: early and late results. Ann Thorac Surg 76:1929-1934 